\title{
A Crystal Chemical Approach to a Cation-Ordered Structure Model for Carbonate-Intercalated Layered Double Hydroxides
}

\author{
K. Jayanthi and P. Vishnu Kamath* \\ Department of Chemistry, Central College, Bangalore University, Bangalore 560 001, India \\ Supporting Information
}

ABSTRACT: Layered double hydroxides comprise a stacking of positively charged metal hydroxide layers with anions and water molecules included in the interlayer galleries. Among the anions, the carbonate ion is the most ubiquitous in both mineral and laboratory synthesized phases. Taylor (1973) suggested that the carbonate ion (molecular symmetry $D_{3 h}$ ) prefers a trigonal prismatic interlayer site (local symmetry $D_{3 h}$ ), whereby the hydrogen bonding with the metal hydroxide layer is maximized. However, the cation ordered structure models of hexagonal symmetry include interlayer sites which are exclusively trigonal antiprisms (local symmetry $D_{3 d}$ ). In keeping with Taylor's criterion, a hexagonal stacking of metal hydroxide layers does not permit the inclusion of carbonate ions in the interlayer. In this work, a crystal chemical approach is adopted based on the translationgleiche subgroups of hexagonal and cubic summits to arrive at a structure model based on the space group $\mathrm{C} 2 / \mathrm{m}$. In this structure, not only is the 3 -fold symmetry of metal coordination retained, but also interlayer sites of $\sim D_{3 h}$ symmetry are generated to host the intercalated carbonate ions. Using this model, the structures of a cohort of carbonate-intercalated layered double hydroxides are refined.

\section{INTRODUCTION}

Among the layered double hydroxides (LDHs), the carbonateintercalated phases are most ubiquitous owing to the affinity of metal hydroxides to $\mathrm{CO}_{2}$ in the ambient ${ }^{1}$ and dissolved carbonates in water. ${ }^{2}$ Consequently the $\mathrm{CO}_{3}{ }^{2-}$-intercalated LDHs are most widely studied for their applications as diverse as catalysts, ${ }^{3}$ fire extinguishers, ${ }^{4}$ antacids, ${ }^{5}$ and electrode materials. ${ }^{6}$ Structural work is greatly impeded by the fact that the $\mathrm{CO}_{3}{ }^{2-}-\mathrm{LDHs}$ crystallize by the incorporation of a large number of stacking faults. Two reasons are provided for the manifestation of faulted structures in the $\mathrm{CO}_{3}{ }^{2-}-\mathrm{LDH}$ systems.

(1) Taylor ${ }^{7}$ opined that the $\mathrm{CO}_{3}{ }^{2-}$ ion prefers polytypes which include interlayer sites having the same local symmetry as its own molecular symmetry $\left(D_{3 h}\right)$. This symmetry matching maximizes the hydrogen bonding between the metal hydroxide layer and the intercalated $\mathrm{CO}_{3}{ }^{2-}$ ion.

(2) Bookin and Drits ${ }^{8}$ pointed out that a multiplicity of polytypes exist which include trigonal prismatic interlayer sites (local site symmetry, $D_{3 h}$ ), prominent among which are the $3 \mathrm{R}_{1}$ and $2 \mathrm{H}_{1}$.

The use of thermodynamic criteria outlined by Verma and Krishna ${ }^{9}$ suggest that competing polytypes with nearly comparable enthalpy content, invariably produce intergrowth structures and when the intergrowth is random, as favored by entropy considerations, faulted structures arise, wherein, however, the principal symmetry axis, parallel to the stacking direction is conserved. The faulted crystals thereby diffract in accord with the Laue symmetry $-3 m$ or $6 / \mathrm{mmm}$ and have been indexed to either rhombohedral or hexagonal cells. ${ }^{10}$

The structural work described hitherto is based on two assumptions of a very fundamental nature.

(1) The divalent and trivalent cations are distributed statistically within the available sites of the metal hydroxide layer $\left[\mathrm{M}_{2}{ }^{2+} \mathrm{M}^{3+}(\mathrm{OH})_{6}\right]$ and thereby the crystal structure is described on the basis of a single $\mathrm{M}\left(\mathrm{M}^{2+}, \mathrm{M}^{\prime 3+}\right)-\mathrm{OH}$ distance. ${ }^{11}$

(2) The anions and water molecules in the interlayer are in a disordered, "liquid like" state ${ }^{12}$ and do not contribute to Bragg scattering by the LDH crystal.

These assumptions, within the ambit of which most powder diffraction results of laboratory-synthesized and crushed mineral LDH samples are discussed, ${ }^{13}$ have been constantly challenged by single crystal studies of mineral LDHs. The early work on pyroaurite single crystals ${ }^{14}$ clearly showed weak spots due to a cation ordered supercell. Diffraction studies on single crystals of certain sulfate-intercalated minerals LDHs such as shigaite showed that the interlayer anions are also ordered and contribute significantly to the intensity of the supercell reflections. $^{15}$

Reasonably well ordered $\mathrm{CO}_{3}{ }^{2-}-\mathrm{LDHs}$ with little or no planar faults have been obtained by homogeneous precipitation by urea hydrolysis. ${ }^{16}$ The use of the Rietveld method has

Received: April 13, 2016

Revised: June 15, 2016

Published: July 5, 2016 
resulted in proposals assigning the $\mathrm{LDH}$ to the structure of the cation-disordered $3 \mathrm{R}_{1}$ polytype. ${ }^{11}$ The primary reason is that the computed intensities of the supercell reflections 100 and 101 of the cation-ordered supercell are only $0.3-1 \%$ relative to the most intense reflection. ${ }^{17}$ Reflections of such low intensity are either (i) not observed in a powder pattern, or (ii) entirely obliterated by the incidence of even a small number of planar faults. Consequently there were no compelling observations in the powder X-ray diffraction (PXRD) patterns to invoke a cation-ordered structure model.

In this paper, we reexamine the powder diffraction data of a cohort of $\mathrm{CO}_{3}{ }^{2-}$-intercalated LDHs and propose a cationordered structure model of monoclinic symmetry which reconciles the results of contrarian investigations that favor a cation-ordered structure.

\section{EXPERIMENTAL SECTION}

The LDH samples studied here are more fully described elsewhere. ${ }^{18,19}$ The LDHs with different combinations of divalent and trivalent metals ions $\left(\mathrm{M}^{2+}=\mathrm{Mg}, \mathrm{Ni}, \mathrm{Co} ; \mathrm{M}^{\prime 3+}=\mathrm{Al}, \mathrm{Ga}\right)$ were homogeneously precipitated by urea hydrolysis $\left(T=140{ }^{\circ} \mathrm{C}, 80 \mathrm{~mL}\right.$ autoclave, autogenous pressure, $50 \%$ filling). The $\left[\mathrm{Cu}-\mathrm{Cr}-\mathrm{CO}_{3}\right]$ $\mathrm{LDH}$ was prepared by anion exchange starting from a $[\mathrm{Cu}-\mathrm{Cr}-\mathrm{Cl}]$ LDH precursor. $^{20}$ The ion exchange was carried out at ambient temperature for $24 \mathrm{~h}$. The product LDHs were washed with warm deionized Type II water (Millipore model ELIX 3 water purification system) and dried at $60{ }^{\circ} \mathrm{C}$ to constant mass. The LDHs were characterized by PXRD using a Bruker D8 Advance powder diffractometer $(\mathrm{Cu} \mathrm{K} \alpha$ source, $\lambda=1.5418 \AA$ ). Data were collected over $5-90^{\circ} 2 \theta$ (step size $0.02^{\circ} 2 \theta$; counting time $10 \mathrm{~s}$ per step). The IR spectra and TGA data of the samples are given in earlier papers. ${ }^{18-20}$

All PXRD patterns were indexed using the PROSZKI ${ }^{21}$ suite of programs to a cell of monoclinic symmetry. Lattice parameters were refined to match all the observed reflections using the lattice constant program APPLEMAN built into the PROSZKI suite and the Figure of Merit (FOM) was determined. Code FOX (Free Objects for Crystallography), ${ }^{22}$ was employed to obtain the Le Bail fit of the PXRD patterns within the space group $C 2 / \mathrm{m}$. Trial cell parameters were defined as $a=\sqrt{ } 3 \times a_{0} ; b=3 \times a_{0} ; c=c_{0} / 3 ; \beta=103.17^{\circ}\left(a_{0}=\right.$ $3.03 \AA$ and $c_{0}=22.68 \AA$ are cell parameters of the cation-disordered rhombohedral cell). The Le Bail fit yielded the refined cell parameters for each of the LDHs.

Rietveld refinement was carried out by using the cell parameters obtained from FOX as input into code GSAS. ${ }^{23} \mathrm{~A}$ TCH pseudo-Voigt line shape function (Profile function 2) with seven variables was used to fit the experimental profile. The refinable profile parameters include asymmetric peak shape, sample displacement, UG, VG, WG and XL, YL for Gaussian and Lorentzian contributions, respectively. The background was corrected using an eight coefficient cosine Fourier series. The structure model was obtained from Krivovichev and coworkers ${ }^{24}$ by shifting the origin to the position of the trivalent cation $\left(\mathrm{M}^{\prime 3+}\right)$ to facilitate comparison with other published structure models. In the first instance, the hydroxyl ion positions of the metal hydroxide layers (O1 and $\mathrm{O} 2)$ were refined. In subsequent cycles, the positions of $\mathrm{O} 1$ and $\mathrm{O} 2$ were fixed, and the position of the intercalated carbonate ion was refined. In this model there are two positions for the carbon atom of the carbonate ions ( $\mathrm{C} 1$ in $4 i$ and $\mathrm{C} 2$ in $8 j$ position), with $\mathrm{O}$ atoms occupying different sites $4 i$, and $8 j$. Bond length $(\mathrm{C}-\mathrm{O}$ $=1.25 \AA \pm 0.1 \AA)$ and bond angle $\left(\mathrm{O}-\mathrm{C}-\mathrm{O}=120^{\circ} \pm 3^{\circ}\right)$ restraints were imposed on the $\mathrm{CO}_{3}{ }^{2-}$ ion, and the position parameters of each atom were refined individually, followed by their site occupancy factors (SOFs). In the model structure, the oxygen atom (Ow) of the intercalated water molecule occupies a special position $(2 d)$. The SOF of Ow was refined in the final cycles keeping the other structural parameters fixed. The resulting structure was visualized at each stage to verify that the evolving structure is chemically reasonable.
SYMGROUP, ${ }^{25}$ a Linux based program was used to determine the coordination symmetry of the metal ions and that of the interlayer site. The Cartesian coordinates corresponding to the six $\mathrm{O}$ atoms coordinated to each metal defines the coordination sphere of the metal ion. The interlayer site is defined by the two closest set of $\mathrm{OH}$ groups belonging to adjacent layers, three above and three below. These were input into the program and symmetry elements extant therein were computed. Symmetry assessment was done based on the scores generated for each symmetry element and they vary from 0 to 100. A score zero signifies the presence of corresponding symmetry element. A score higher than zero indicates the extent of deviation from the exact symmetry.

\section{RESULTS AND DISCUSSION}

A feature common to all brucite-based structures $\left(C_{6}\right.$ type $)$ is the existence of a 3 -fold rotation axis at all three levels of structural hierarchy:

(i) at the metal coordination polyhedron (point group $D_{3 d}$ ),

(ii) at the metal hydroxide layer (layer group $p-3 m 1$ also written as $p-32 / m 1)$, and

(iii) the whole crystal which defines the crystal symmetry (space group $P \overline{3} m 1$ ).

The two highest symmetry space groups defined by the existence of a principal axis 3-axis are $P m \overline{3} \mathrm{~m}$ and $P 6 / \mathrm{mmm}$, belonging respectively to the cubic (Scheme 1) and hexagonal

Scheme 1. Graphs of the Translationgleiche Subgroup with a Cubic Summit

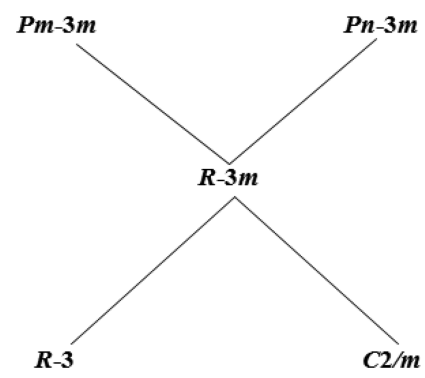

symmetries (Scheme 2). Given the anisotropy in bonding among LDHs, a cubic symmetry is not physically tenable, which leads us to $R \overline{3} m$, a principal subgroup of $P m \overline{3} m$.

In keeping with these considerations, mineral pyroaurite $\left(\left[\mathrm{Mg}-\mathrm{Fe}-\mathrm{CO}_{3}\right] \mathrm{LDH}\right)$ is assigned to the $R \overline{3} m$ space group and mineral sjogrenite a polytypic modification of pyroaurite is assigned to $P 6_{3} / m m c .{ }^{14}$ The latter is closely related to the $P 6 /$ $\mathrm{mmm}$ space group. Within these structure models, the metal hydroxide layers are defined by two close packed arrays of

Scheme 2. Graphs of the Translationgleiche Subgroup with a Hexagonal Summit

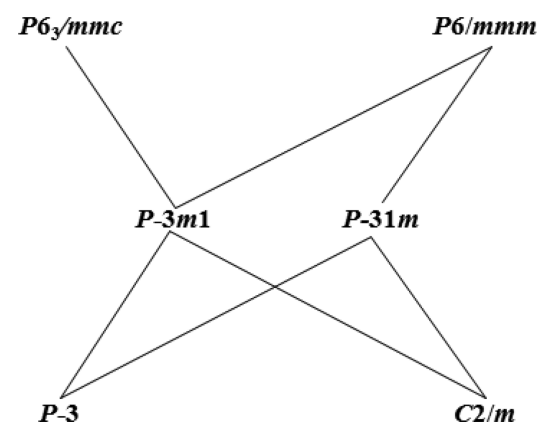


hydroxyl ions with the $\mathrm{Mg}^{2+}$ and $\mathrm{Fe}^{3+}$ cations occupying all the six-coordinate interstitial sites statistically (coordination symmetry $D_{3 d}$ ). Each 2 -D array of hydroxyl ions is perfectly hexagonal. The metal hydroxide layer can be described as $\mathrm{AbC}$ or simply as $\mathrm{AC}$ (A, C: represent close packed $\mathrm{OH}^{-}$ion positions and $\mathrm{b}$ : octahedral interstitial site).

The pyroaurite structure has the stacking sequence $\mathrm{AC}=\mathrm{CB}$ $=\mathrm{BA}=\mathrm{AC} \cdots \cdot .\left(\right.$ polytype $\left.3 \mathrm{R}_{1}\right)$, and sjogrenite has the stacking sequence $\mathrm{AC}=\mathrm{CA}=\mathrm{AC} \cdots \cdots\left(\right.$ polytype $\left.2 \mathrm{H}_{1}\right)$. The two structures enclose interlayer sites of trigonal prismatic symmetry shown by the symbol "=”. All these structures models are pseudo single cation phases and comprise brucitelike layers with $a=b \approx 3.1 \AA$. When the metal hydroxide layers are stacked in the sequence AC-AC..... (polytype $1 H$ ), the resultant space group $P \overline{3} \mathrm{ml}$ is a subgroup of $P 6_{3} / m m c$ and also incidentally of $P 6 / \mathrm{mmm}$. Single cation hydroxides such as minerals brucite, $\mathrm{Mg}(\mathrm{OH})_{2}$, and theophrastite, $\mathrm{Ni}(\mathrm{OH})_{2}$, belong to this space group. ${ }^{26}$

To conclude, the summits of the hexagonal and cubic symmetries and their principal subgroups correspond to structures of (pseudo) single cation hydroxide phases.

In light of recent spectroscopic ${ }^{27-29}$ and crystallographic evidence $^{20,24,30}$ which favors cation ordering, structure models for $\mathrm{LDHs}$ based on the $3 \mathrm{R}_{1}$ and $2 \mathrm{H}_{1}$ polytypic modifications of single cation hydroxides phases stand discredited. In particular, the observation of supercell reflections arising from a hexagonal cell $a=b \approx \sqrt{ } 3 \times a_{0}\left(a_{0} \approx 3.13 \AA\right)^{24,30}$ shows that the trivalent cation is in an ordered arrangement with respect to the divalent cation. As the $\left[\mathrm{M}^{\prime 3+}(\mathrm{OH})_{6}\right]$ polyhedron has a smaller size compared to the $\left[\mathrm{M}^{2+}(\mathrm{OH})_{6}\right]$ polyhedron, cation ordering causes a nonuniform distention of the metal hydroxide layer. The net effect of cation ordering manifests itself in the following manner at different levels of structural hierarchy.

(i) The 2-D arrays of hydroxyl ions lose the hexagonal symmetry resulting in three in-plane nonbonded HO--$\mathrm{OH}$ distances. ${ }^{31}$

(ii) The divalent metal coordination symmetry is reduced from $D_{3 d}$ to $C_{3}{ }^{20}$

(iii) A single metal hydroxide layer acquires the layer group $p$ $31 \mathrm{~m}$ also written as $p-312 / \mathrm{m}$.

This cation-ordered layer group has distinctly fewer symmetry elements than $p-3 m 1$, and the 3 -fold symmetry is marshaled only by increasing the size of the unit mesh (Figure 1).

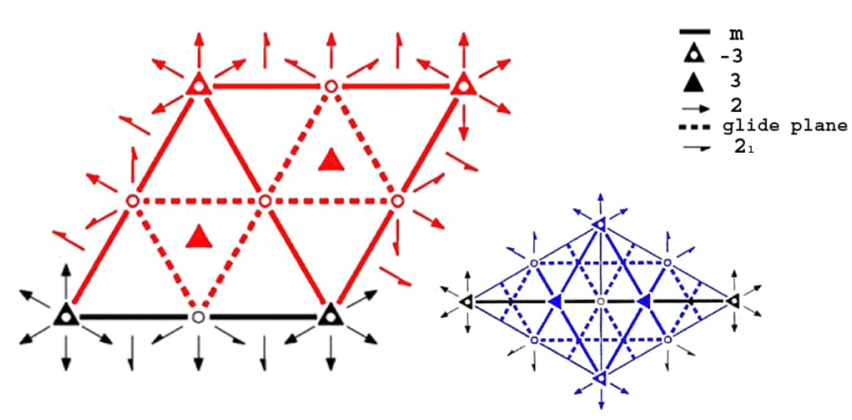

(a)

(b)

Figure 1. Layer group representations of (a) $p-31 m$ and (b) $p-3 m 1$. The mirror plane represented by the bold black line is common to the two layer groups.
A decrease in the symmetry of the layer group is expected to bring about a concomitant reduction in crystal symmetry. The two possible subgroups of $R \overline{3} m$ with a progressive decrease in symmetry are $R \overline{3}$ and $R 3$ (Scheme 1 ). The LDHs of $\mathrm{Ca}$ and $\mathrm{Al}$ are indeed assigned to $R \overline{3} .^{32}$ To the best of the authors' knowledge, no LDHs are as yet assigned to $R 3$.

In the hexagonal lineage, an idealized cation-ordered metal hydroxide layer without any distortion would belong to the space group $P-31 \mathrm{~m}$ space group (a subset of both $P 6 / \mathrm{mmm}$ and $\left.P 6_{3} / m m c\right)$ with $a=b=\sqrt{3} \times a_{0}\left(a_{0}=3.11 \AA\right.$ of the brucite layer). ${ }^{33}$ Since such an idealized layer is physically untenable, the nonuniform distention of the metal hydroxide layer on cation-ordering leads to the subgroup $P \overline{3}$ (Scheme 2 ).

The first attempt to reconcile the decrease in the symmetry of the metal hydroxide layer with the Laue symmetry of the LDH crystals was made by Hofmeister and Von Platen, ${ }^{34}$ who suggested a structure model of space group $P 3_{1}\left(a=\sqrt{ } 3 \times a_{0}=\right.$ $5.27 \AA ; c=c_{0}=22.8 \AA$ ) for the cation-ordered 2:1 LDHs. This model was predicated on the basis of separate sites for the two divalent ions and the trivalent ion. The presence of the screw axis ensured a 3-fold multiplicity for all the sites, all of which were general positions $(x, y, z)$. The six hydroxyl oxygen atom positions were chosen so as to yield realistic values for the $\mathrm{M}^{2+}-\mathrm{OH}$ and $\mathrm{M}^{\prime 3+}-\mathrm{OH}$ bond distances.

The choice of the $P 3_{1}$ space group is somewhat unusual for two reasons: (i) $P 3_{1}$ does not appear directly in the hierarchy of subgroups of either the cubic or the hexagonal lineage, and (ii) the chosen cell parameters yield a very large cell volume $548 \AA^{3}$, much higher than that of related structures $\left(\sim 370 \AA^{3}\right) .^{34} \mathrm{~A}$ simulation of the PXRD pattern of the $P 3_{1}$ structure (Figure 2)

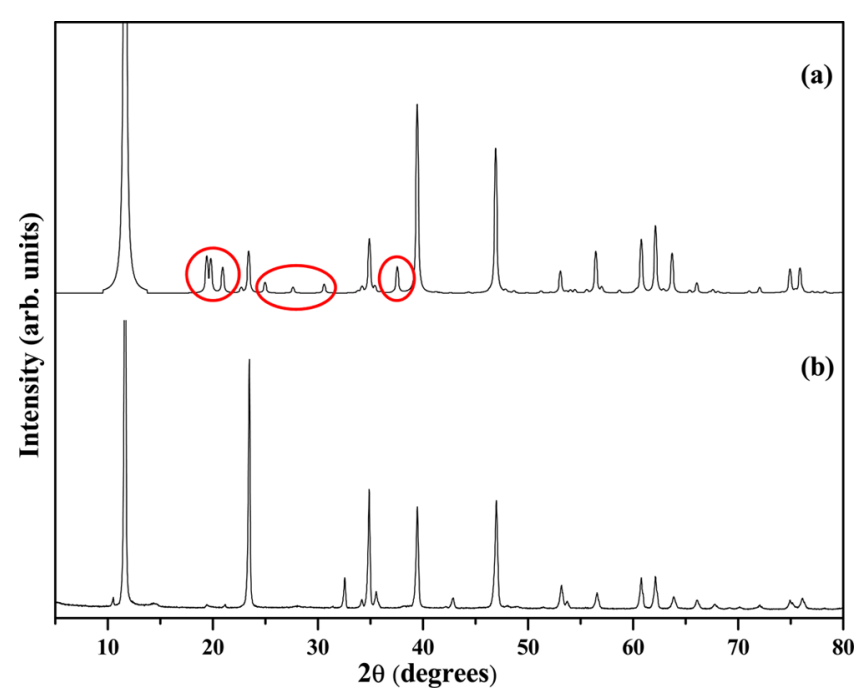

Figure 2. (a) Simulation of the PXRD pattern of a cation-ordered $P 3_{1}$ structure of magaldrate compared with (b) the observed PXRD pattern of $\left[\mathrm{Mg}-\mathrm{Al}-\mathrm{CO}_{3}\right] \mathrm{LDH}$.

yields numerous additional reflections as expected of a large unit cell. These reflections have a low intensity $(<1 \%)$ and appear at Bragg angles quite distant from the observed ones. In the absence of specific observations to support the $P 3_{1}$ structure model, it could be abandoned in favor of a more logically chosen alternative. The logical choice falls to $R \overline{3} \subseteq R \overline{3} m$ (in cubic lineage) and $P \overline{3} \subseteq P-31 m$ (hexagonal lineage). The sulfate-intercalated 2:1 LDHs were indexed to a hexagonal cell, thereby ruling out the rhombohedral space groups. The structures were refined within the space group $P \overline{3}(a=b=$ 
$\left.\sqrt{ } 3 \times a_{0} ; c=c_{0} / 3\right) .{ }^{30}$ This structure is obtained by stacking the cation-ordered metal hydroxide layer (layer group $p-31 \mathrm{~m}$ ) (Figure 1a) one above another using the stacking vector $(0,0$, 1) to yield a one-layer polytype of hexagonal symmetry, designated as $1 \mathrm{H}$. This choice of the unit cell in the sulfateintercalated LDHs was made easy due to the observation of the supercell reflections 100 and 101 of the enlarged unit mesh of the metal hydroxide layer. The absence of these supercell reflections in the PXRD patterns of carbonate-intercalated LDHs (see Figure 2 for a representative pattern) renders the choice of the $P \overline{3}$ cell counterintuitive. Additionally, the observed PXRD patterns could not be indexed to a hexagonal cell.

Nevertheless at this point in the narrative, it would be instructive to compare the unit mesh of the $P \overline{3}$ structure model with that of the $P 3_{1}$ structure model (Figure 3 ). A comparison

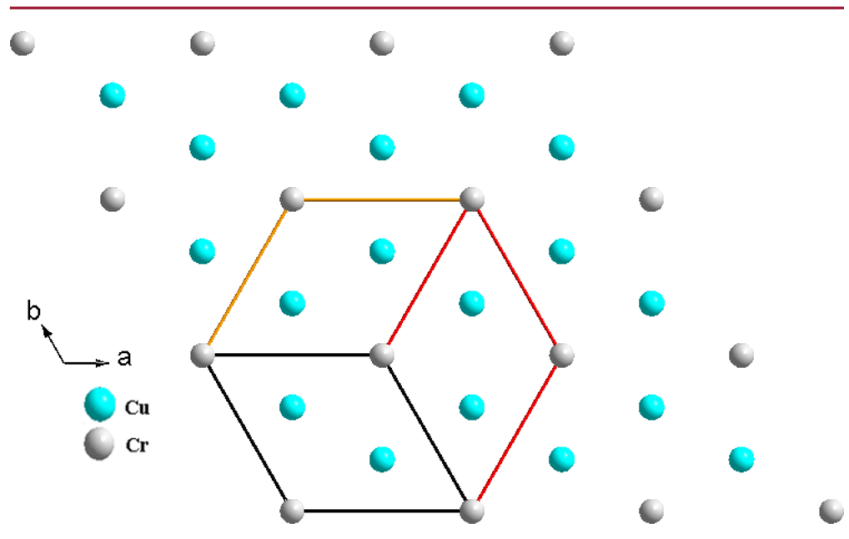

Figure 3. A $3 \times 3$ mesh of a cation-ordered metal hydroxide layer. The unit mesh in black is seen to generate the fragments given in color by successive operation of a $33_{1}$ screw.

of the metal ion positions of the two shows that the origin in the $P 3_{1}$ structure model is shifted from the origin in the $P \overline{3}$ model by $(2 / 9,1 / 9) .{ }^{34}$ This shift is better understood by taking $3 \times 3$ sized mesh of the cation-ordered metal hydroxide layer. Within the ambit of this enlarged fragment a (2/9, 1/9) translation is equivalent to a $(2 / 3,1 / 3)$ shift of the $1 \times 1$ sized mesh. The application of a $33_{1}$ screw generates additional fragments of the $3 \times 3$ sized mesh in projection on the $a-b$ plane. It is evident that $P 3_{1}$ structure model is identical to the $P \overline{3}$ structure model, with a needless expansion along the $c$ crystallographic axis. Despite this equivalence, the observed PXRD pattern (Figure 2) could not be indexed to a one-layer hexagonal cell. Hence the need to select an enlarged cell in the space group $P 3_{1}$.

At this juncture having rejected rhombohedral symmetry and the $P \overline{3}$ space group, we decided it prudent to explore a structure model of a lower crystal symmetry. The right arm of the hierarchy of space groups of both the cubic and hexagonal lineage lead us the monoclinic space group $C 2 / \mathrm{m}$. In this structure model of $c$-stacking, the unit mesh is obtained from the very same layer group as that of the $P \overline{3}$ structure, with, however, differently chosen parameters $a=\sqrt{ } 3 \times a_{0} ; b=3 \times$ $a_{0} \cdot{ }^{35}$ In this structure model, the metal hydroxide layers shown in Figure 1a are stacked at an angle $\beta \neq 90^{\circ}$. This tilt destroys the coincidence of the 3 -fold axes of successive layers, while retaining the in-plane 2 -fold axes. Such a stacking vector, following the structural synthon approach, ${ }^{36}$ yields a monoclinic crystal. Such a model was proposed by Thiel and
Poeppelmeier $^{37}$ for the Li-Al (I-III) LDHs, wherein cation ordering is well-known. This model was adapted further for the hydrotalcite-like II-III LDHs by Krivovichev and co-workers. ${ }^{24}$

Accordingly the PXRD patterns of a cohort of $\mathrm{CO}_{3}{ }^{2-}$ intercalated LDHs were indexed to a monoclinic cell (Table S1) with satisfactory figures of merit. A Rietveld fit of the diffraction profile of the $\left[\mathrm{Cu}-\mathrm{Cr}-\mathrm{CO}_{3}\right] \mathrm{LDH}$ (Figure 4) yields

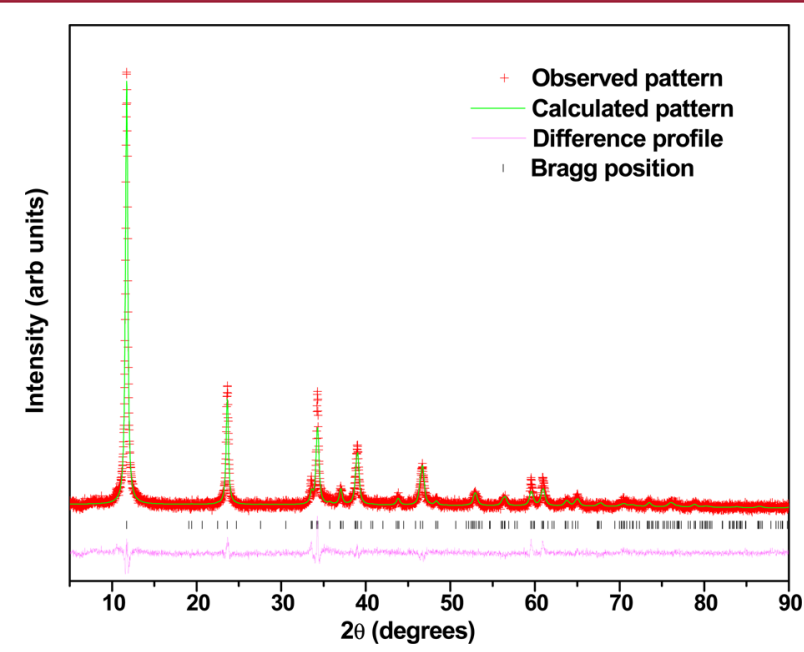

Figure 4. Rietveld fit of the PXRD pattern of the $\left[\mathrm{Cu}-\mathrm{Cr}-\mathrm{CO}_{3}\right]$ LDH.

a featureless difference profile and satisfactory goodness of fit parameters (Table 1). This fit is representative of similar fits carried out on the cohort of $\mathrm{CO}_{3}{ }^{2-}$-intercalated LDHs (Table 1, Figures S1-S6, Tables S2-S7). All the Rietveld fits were carried out using the structure model proposed by Krivovichev and co-workers. ${ }^{24}$ The refined structure of the $\left[\mathrm{Cu}-\mathrm{Cr}-\mathrm{CO}_{3}\right]$ $\mathrm{LDH}$ (Figure 5, Table 2) reveals that the successive metal hydroxide layers are rigidly translated relative to one another. The close relationship between the metal hydroxide layer of the previously reported $\left[\mathrm{Cu}-\mathrm{Cr}-\mathrm{SO}_{4}\right] \mathrm{LDH}^{20}$ (space group $P \overline{3}$ ) and the present structure is evident from the following observations.

(1) The $a$ and $b$ cell parameters are related as $a_{\mathrm{m}} \approx a_{\mathrm{h}}$ and $b_{\mathrm{m}}$ $\approx \sqrt{3} \times a_{\mathrm{h}}(\mathrm{m}$ : monoclinic; $\mathrm{h}$ : hexagonal) showing that in 2-D the metal hydroxide later is invariant in the two structures models, and the change in crystal symmetry is brought about by an altered stacking angle $\left(\beta \neq 90^{\circ}\right)$.

(2) The $\left[\mathrm{Cr}(\mathrm{OH})_{6}\right]$ polyhedron retains the $D_{3 d}$ coordination symmetry as evaluated by code SYMGROUP (Table 3 ), while the coordination symmetry of the $\left[\mathrm{Cu}(\mathrm{OH})_{6}\right]$ polyhedron is $\mathrm{D}_{3}$ in the $\left[\mathrm{Cu}-\mathrm{Cr}-\mathrm{CO}_{3}\right] \mathrm{LDH}$ (space group $\mathrm{C} 2 / \mathrm{m}$ ) in comparison with the $C_{3}$ symmetry in the sulfate analogue (space group $P \overline{3}$ ). The difference in the coordination symmetries of the $\left[\mathrm{Cu}(\mathrm{OH})_{6}\right]$ polyhedron in the two structures is only one of degree and arises out of the different limiting scores employed to predict the existence of a symmetry element.

What are the changes brought about in the interlayer due to the relative translation of the metal hydroxide layer? The value of the stacking angle $\beta \approx 103^{\circ}$ corresponds to a relative translation of $(1 / 3,0)$ between the successive metal hydroxide layers. This alters the local symmetry of the interlayer sites. An interlayer site is formed by the six closest hydroxyl ions, three each drawn from the upper and the lower metal hydroxide 
Table 1. Results of Structure Refinement of Carbonate-Intercalated Layered Double Hydroxides Using a Structure Model of Monoclinic Symmetry (Space Group C2/m)

\begin{tabular}{|c|c|c|c|c|c|c|c|}
\hline $\mathrm{LDH}$ & {$[\mathrm{Cu}-\mathrm{Cr}]$} & {$[\mathrm{Mg}-\mathrm{Al}]$} & {$[\mathrm{Ni}-\mathrm{Al}]$} & {$[\mathrm{Zn}-\mathrm{Al}]$} & {$[\mathrm{Co}-\mathrm{Ga}]$} & {$[\mathrm{Ni}-\mathrm{Ga}]$} & {$[\mathrm{Zn}-\mathrm{Ga}]$} \\
\hline$a(\AA)$ & $5.385(1)$ & $5.282(6)$ & $5.234(7)$ & $5.312(2)$ & $5.391(8)$ & $5.332(6)$ & $5.392(7)$ \\
\hline$b(\AA)$ & $9.301(2)$ & $9.143(1)$ & $9.066(2)$ & $9.213(6)$ & $9.339(2)$ & $9.187(4)$ & $9.344(1)$ \\
\hline$c(\AA)$ & $7.734(7)$ & $7.771(4)$ & $7.715(4)$ & $7.747(9)$ & $7.761(4)$ & $7.799(8)$ & $7.814(4)$ \\
\hline$\beta(\mathrm{deg})$ & $103.08(3)$ & $102.92(1)$ & $102.67(2)$ & $102.97(5)$ & $103.53(2)$ & $102.67(9)$ & $103.07(9)$ \\
\hline volume $/ \AA^{3}$ & $377.29(5)$ & $365.83(8)$ & $357.14(3)$ & $369.49(5)$ & $379.87(6)$ & $371.20(3)$ & $383.51(3)$ \\
\hline parameters refined & 46 & 46 & 46 & 46 & 46 & 46 & 46 \\
\hline$R_{\mathrm{wp}}$ & 0.0779 & 0.1645 & 0.0560 & 0.1536 & 0.1640 & 0.1257 & 0.1186 \\
\hline$R_{\mathrm{p}}$ & 0.0619 & 0.1309 & 0.0424 & 0.1240 & 0.1291 & 0.0942 & 0.0956 \\
\hline$R\left(F^{2}\right)$ & 0.2069 & 0.1771 & 0.1332 & 0.1424 & 0.2094 & 0.1985 & 0.1370 \\
\hline
\end{tabular}
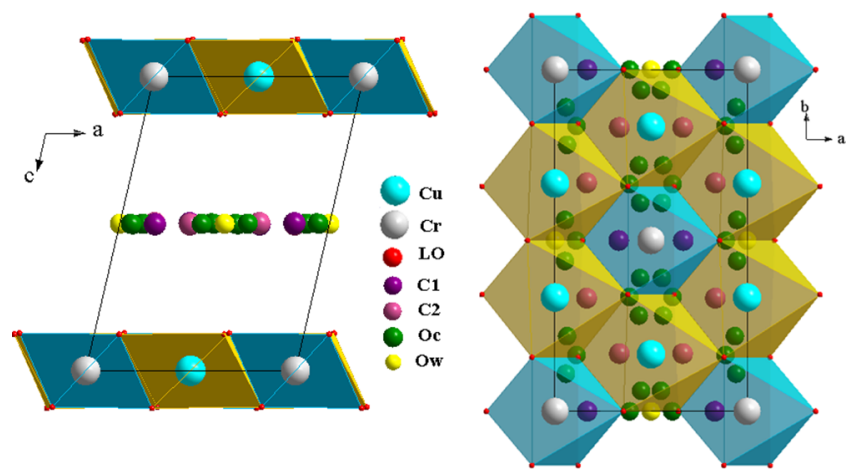

Figure 5. Refined structure of the $\left[\mathrm{Cu}-\mathrm{Cr}-\mathrm{CO}_{3}\right] \mathrm{LDH}$ (a) viewed along the $b$ axis showing the layer and the interlayer with carbonate ions, and (b) viewed along the $c$ axis showing two distinct sites for the $\mathrm{Cu}$ and $\mathrm{Cr}$ atoms.

Table 2. Refined Atomic Position Parameters of the $[\mathrm{Cu}-$ $\left.\mathrm{Cr}-\mathrm{CO}_{3}\right]$ Layered Double Hydroxide

\begin{tabular}{lcllll} 
atom & Wyckoff position & \multicolumn{1}{c}{$x$} & \multicolumn{1}{c}{$y$} & \multicolumn{1}{c}{$z$} & SOFs \\
$\mathrm{Cu}$ & $4 g$ & 0 & 0.6669 & 0 & 1.0 \\
$\mathrm{Cr}$ & $2 a$ & 0 & 0 & 0 & 1.0 \\
$\mathrm{O} 1$ & $8 j$ & 0.1200 & 0.8417 & 0.8762 & 1.0 \\
$\mathrm{O} 2$ & $4 i$ & 0.6431 & 0 & 0.8725 & 1.0 \\
$\mathrm{H} 1$ & $4 i$ & 0.5940 & 0 & 0.7425 & 1.0 \\
$\mathrm{H} 2$ & $8 j$ & 0.0677 & 0.8401 & 0.7437 & 1.0 \\
$\mathrm{O} 11$ & $4 i$ & 0.6101 & 0 & 0.4990 & 0.1610 \\
$\mathrm{O} 12$ & $8 j$ & 0.0570 & 0.890 & 0.5010 & 0.1590 \\
$\mathrm{O} 21$ & $8 j$ & 0.5520 & 0.940 & 0.5000 & 0.1380 \\
$\mathrm{O} 22$ & $8 j$ & 0.9370 & 0.780 & 0.4980 & 0.1671 \\
$\mathrm{O} 23$ & $8 j$ & 0.8880 & 0.835 & 0.4990 & 0.1454 \\
$\mathrm{C} 1$ & $4 i$ & 0.8320 & 0 & 0.4980 & 0.0810 \\
$\mathrm{C} 2$ & $8 j$ & 0.6650 & 0.8311 & 0.4980 & 0.0840 \\
$\mathrm{Ow}$ & $2 d$ & 0.5000 & 0 & 0.5000 & 0.2390 \\
\hline
\end{tabular}

layers. While in the $P \overline{3}$ structure model, interlayer sites of only $D_{3 d}$ symmetry can be identified, in the $C 2 / m$ structure model proposed in this work, two different cages can be identified in the interlayer region, defined by interlayer $\mathrm{HO}---\mathrm{OH}$ distances of $\sim 5.64 \AA$ and $\sim 6.40 \AA$ respectively (Figure 6a). The smaller cage is formed by nearly eclipsed $\mathrm{OH}$ groups and has a $\sim D_{3 h}$ symmetry (Table 4). In the refined structure, there are two positions for the carbonates ions identified by the two carbons $\mathrm{C} 1$ and $\mathrm{C} 2$. It is seen that both $\mathrm{C} 1$ and $\mathrm{C} 2$ occupy cages of $D_{3 h}$ symmetry with comparable $\mathrm{C}-\mathrm{OH}$ nonbonded distances $(3.34$ $\pm 0.06 \AA$ ) (Figure $6 \mathrm{~b}$ ). From these observations, it is evident that despite the reduction in crystal symmetry due to cation ordering, Taylor's criterion continues to operate. The operation
Table 3. Metal Coordination Symmetry in the $[\mathrm{Cu}-\mathrm{Cr}]$ LDH Layer in Different Structure Models

\begin{tabular}{|c|c|c|c|}
\hline \multicolumn{4}{|c|}{$\left[\mathrm{Cu}(\mathrm{OH})_{6}\right]$ polyhedron } \\
\hline \multicolumn{2}{|c|}{$P \overline{3}$} & \multicolumn{2}{|c|}{$\mathrm{C} 2 / \mathrm{m}$} \\
\hline $\begin{array}{l}\text { symmetry } \\
\text { elements }\end{array}$ & scores & $\begin{array}{l}\text { symmetry } \\
\text { elements }\end{array}$ & scores \\
\hline $3 C_{2}$ & $\begin{array}{l}\text { 0.0687, } 0.0687 \\
0.0687\end{array}$ & $3 C_{2}$ & $\begin{array}{l}0.0000,0.0046 \\
0.0046\end{array}$ \\
\hline$C_{3}$ & 0.0000 & $\mathrm{C}_{3}$ & 0.0061 \\
\hline \multicolumn{2}{|c|}{$C_{3}$ point group } & \multicolumn{2}{|c|}{$D_{3}$ point group } \\
\hline \multicolumn{4}{|c|}{$\left[\mathrm{Cr}(\mathrm{OH})_{6}\right]$ polyhedron } \\
\hline \multicolumn{2}{|c|}{$P \overline{3}$} & \multicolumn{2}{|c|}{$\mathrm{C} 2 / \mathrm{m}$} \\
\hline $\begin{array}{l}\text { symmetry } \\
\text { elements }\end{array}$ & scores & $\begin{array}{l}\text { symmetry } \\
\text { elements }\end{array}$ & scores \\
\hline $3 C_{2}$ & $\begin{array}{l}0.0000,0.0000 \\
0.0000\end{array}$ & $3 C_{2}$ & $\begin{array}{l}0.0000,0.0003, \\
0.0003\end{array}$ \\
\hline$C_{3}$ & 0.0000 & $C_{3}$ & 0.0004 \\
\hline $\begin{array}{l}\text { mirror planes } \\
\left(3 \sigma_{\mathrm{d}}\right)\end{array}$ & $\begin{array}{l}0.0000,0.0000 \\
0.0000\end{array}$ & $\begin{array}{l}\text { mirror planes } \\
\left(3 \sigma_{\mathrm{d}}\right)\end{array}$ & $\begin{array}{l}0.0000,0.0003 \\
\quad 0.0003\end{array}$ \\
\hline$S_{6}$ & 0.0000 & $S_{6}$ & 0.0004 \\
\hline$i$ & 0.0000 & $i$ & 0.0000 \\
\hline \multicolumn{2}{|c|}{$D_{3 d}$ point group } & \multicolumn{2}{|c|}{$D_{3 d}$ point group } \\
\hline
\end{tabular}

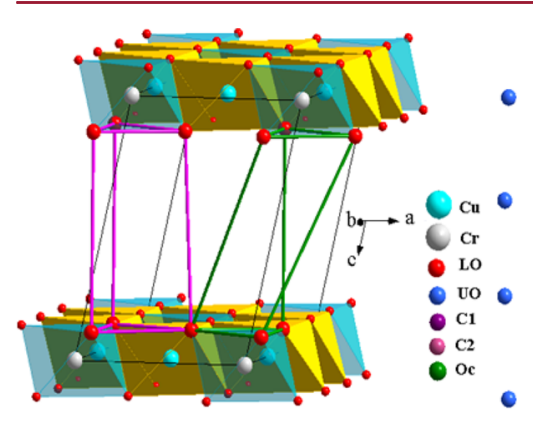

(a)

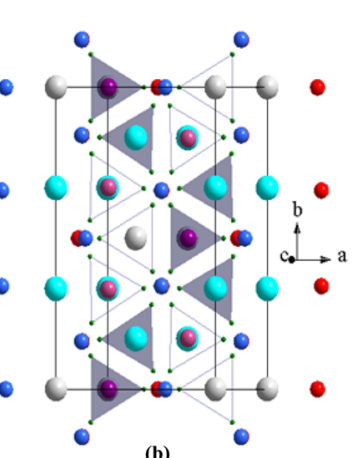

(b)
Figure 6. (a) The two different cages formed in the interlayer gallery of the $[\mathrm{Cu}-\mathrm{Cr}] \mathrm{LDH}$. (b) Carbon atoms $\mathrm{C} 1$ and $\mathrm{C} 2$ are seen to occupy the cages of $D_{3 h}$ local symmetry. The lower (red) and upper (blue) hydroxyl ions defining the cages are seen to be approximately eclipsed.

of the Taylor's criterion is facilitated by the translation of layers relative to one another. The enthalpy gain obtained by matching the local symmetry of the interlayer site with that of the molecular symmetry of the anion appears to be the driving force for the translation of adjacent layers relative to one another. 
Table 4. Symmetry of the Interlayer Sites in Different Structure Models Proposed for the $[\mathrm{Cu}-\mathrm{Cr}]$ Layered Double Hydroxide

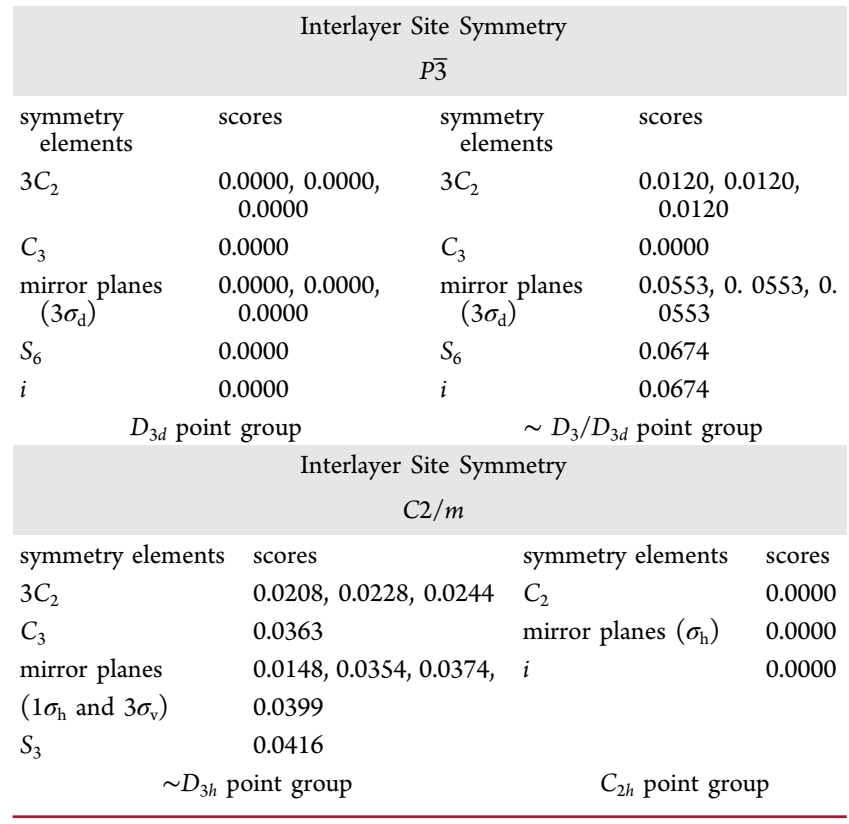

\section{CONCLUSION}

The well-known cation-ordered hexagonal structure model (space group $P \overline{3}$ ) does not provide interlayer sites of local symmetry, $D_{3 h}$. However, carbonate-intercalated phases are ubiquitous among minerals and laboratory preparations. In this work a crystal chemical approach based on descending symmetry is employed to arrive at a structure model within the space group $\mathrm{C} 2 / \mathrm{m}$ that generates interlayer sites of local symmetry $D_{3 h}$.

\section{ASSOCIATED CONTENT}

\section{S Supporting Information}

The Supporting Information is available free of charge on the ACS Publications website at DOI: 10.1021/acs.cgd.6b00562.

Observed $2 \theta$ values of carbonate-intercalated layered double hydroxides with the corresponding indices obtained from PROSZKI. Rietveld fits of the PXRD patterns of the $\left[\mathrm{M}^{2+}-\mathrm{M}^{\prime 3+}-\mathrm{CO}_{3}\right] \mathrm{LDHs}\left(\mathrm{M}^{2+}=\mathrm{Mg}, \mathrm{Ni}\right.$, $\left.\mathrm{Co}, \mathrm{Zn} ; \mathrm{M}^{\prime 3+}=\mathrm{Al}, \mathrm{Ga}\right)$ and their corresponding refined atomic position parameters (PDF)

\section{Accession Codes}

Further details on crystal structure are available from the Cambridge Crystallography Data Centre, CCDC No. 1447343 for $\left[\mathrm{Mg}-\mathrm{Al}-\mathrm{CO}_{3}\right] \mathrm{LDH}, \mathrm{CCDC}$ No. 1447344 for $[\mathrm{Zn}-\mathrm{Ga}-$ $\left.\mathrm{CO}_{3}\right] \mathrm{LDH}, \mathrm{CCDC}$ No. 1447346 for $\left[\mathrm{Cu}-\mathrm{Cr}-\mathrm{CO}_{3}\right] \mathrm{LDH}$, CCDC No. 1447354 for $\left[\mathrm{Co}-\mathrm{Ga}-\mathrm{CO}_{3}\right] \mathrm{LDH}, \mathrm{CCDC}$ No. $1447355\left[\mathrm{Ni}-\mathrm{Al}-\mathrm{CO}_{3}\right] \mathrm{LDH}, \mathrm{CCDC}$ No. $1447365[\mathrm{Zn}-\mathrm{Al}-$ $\left.\mathrm{CO}_{3}\right] \mathrm{LDH}$, and CCDC No. $1447380\left[\mathrm{Ni}-\mathrm{Ga}-\mathrm{CO}_{3}\right] \mathrm{LDH}$. These data can be obtained free of charge via www.ccdc.cam.ac.uk/data_request/cif, or by emailing data_request@ccdc. cam.ac.uk, or by contacting The Cambridge $\bar{C}$ rystallographic Data Centre, 12 Union Road, Cambridge CB2 1EZ, UK; fax: +44 1223336033 .

\section{AUTHOR INFORMATION}

\section{Corresponding Author}

*E-mail: vishnukamath8@hotmail.com.

\section{Notes}

The authors declare no competing financial interest.

\section{ACKNOWLEDGMENTS}

Authors thank Dr. G. V. Manohara for providing the LDH samples for this study. Authors also thank the Department of Science and Technology (DST), Government of India (GOI), for financial support. K.J. thanks the Council of Scientific Industrial Research, GOI for the award of a senior research fellowship.

\section{REFERENCES}

(1) Ficicilar, B.; Dogu, T. Catal. Today 2006, 115, 274.

(2) Miyata, S. Clays Clay Miner. 1983, 31, 305.

(3) Cavani, F.; Trifiro, F.; Vaccari, A. Catal. Today 1991, 11, 173.

(4) Wang, X. D.; Zhang, Q. Polym. Int. 2004, 53, 698.

(5) Playle, A. C.; Gunning, S. R.; Llewellyn, A. F. Pharm. Acta Helv. 1974, 49, 298.

(6) Buss, D. H.; Bauer, J.; Diembeck, W.; Glemser, O. J. Chem. Soc., Chem. Commun. 1985, 81.

(7) Taylor, H. F. W. Mineral. Mag. 1973, 39, 377.

(8) Bookin, A. S.; Drits, V. A. Clays Clay Miner. 1993, 41, 551.

(9) Verma, A. R.; Krishna, P. Polymorphism and Polytypism. In Crystals; John Wiley: New York, 1966.

(10) Radha, S.; Kamath, P. V.; Kannan, S. Z. Anorg. Allg. Chem. 2012, 638, 2317.

(11) Richardson, I. G. Acta Crystallogr., Sect. B: Struct. Sci., Cryst. Eng. Mater. 2013, 69, 150.

(12) Khan, A. I.; O’Hare, D. J. Mater. Chem. 2002, 12, 3191.

(13) Mills, S. J.; Christy, A. G.; Genin, J. M. R.; Kameda, T.; Colombo, F. Mineral. Mag. 2012, 76, 1289.

(14) Taylor, H. F. W. Mineral. Mag. 1969, 37, 338.

(15) Cooper, M. A.; Hawthorne, F. C. Can. Mineral. 1996, 34, 91.

(16) Costantino, U.; Marmottini, F.; Nocchetti, M.; Vivani, R. Eur. J. Inorg. Chem. 1998, 1998, 1439.

(17) Roussel, H.; Briois, V.; Elkaim, E.; de Roy, A.; Besse, J. P. J. Phys. Chem. B 2000, 104, 5915.

(18) Radha, A. V.; Kamath, P. V.; Shivakumara, C. Acta Crystallogr., Sect. B: Struct. Sci. 2007, 63, 243.

(19) Manohara, G. V.; Kamath, P. V. Bull. Mater. Sci. 2010, 33, 325.

(20) Jayanthi, K.; Kamath, P. V. Dalton Trans. 2013, 42, 13220.

(21) Lasocha, W.; Lewiniski, K. PROSZKI, A System of Programs for Powder Diffraction Data Analysis, ver-2.4; Jagiellonian University: Krakow, Poland, 1994.

(22) Fox, Free Objects for Crystallography, http://objcryst. sourceforge.net.

(23) Larson, A. C.; Von Dreele, R. B. General Structure Analysis System (GSAS). Los Alamos National Laboratory Report LAUR; Los Alamos National Laboratory: Los Alamos, NM, 2004, 86.

(24) Krivovichev, S. V.; Yakovenchuk, V. N.; Zhitova, E. S.; Zolotarev, A. A.; Pakhomovsky, Y. A.; Ivanyuk, G. Yu. Mineral. Mag. 2010, 74, 833.

(25) Casanova, D.; Alemany, P.; Alvarez, S. SYMOP; Universidad de Barcelona: Barcelona, Spain, 2007.

(26) Marcopoulos, T.; Economou, M. Am. Mineral. 1981, 66, 1020.

(27) Vucelic, M.; Jones, W.; Moggridge, G. D. Clays Clay Miner. 1997, 45, 803.

(28) Sideris, P. J.; Nielsen, U. G.; Gan, Z.; Grey, C. P. Science 2008, $321,113$.

(29) Sideris, P. J.; Blanc, F.; Gan, Z.; Grey, C. P. Chem. Mater. 2012, 24, 2449.

(30) Radha, S.; Kamath, P. V. Inorg. Chem. 2013, 52, 4834.

(31) Radha, S.; Jayanthi, K.; Breu, J.; Kamath, P. V. Clays Clay Miner. 2014, 62, 53. 
(32) Rousselot, I.; Taviot-Gueho, C.; Leroux, F.; Leone, P.; Palvadeau, P.; Besse, J. P. J. Solid State Chem. 2002, 167, 137.

(33) Mookherjee, M.; Stixrude, L. Am. Mineral. 2006, 91, 127.

(34) Hofmeister, W.; Von Platen, H. Crystallogr. Rev. 1992, 3 , 3.

(35) Marappa, S.; Kamath, P. V. Ind. Eng. Chem. Res. 2015, 54, 11075.

(36) Jayanthi, K.; Nagendran, S.; Kamath, P. V. Inorg. Chem. 2015, $54,8388$.

(37) Thiel, J. P.; Chiang, C. K.; Poeppelmeier, K. R. Chem. Mater. 1993, 5, 297. 